First Peoples Child \& Family Review

A Journal on Innovation and Best Practices in Aboriginal Child Welfare Administration, Research, Policy \& Practice

\title{
Can University/Community Collaboration Create Spaces for Aboriginal Reconciliation?
} Case Study of the Healing of the Seven Generations and Four
Directions Community Projects and Wilfrid Laurier University

\section{Ginette Lafrenière, Papa Lamine Diallo, Donna Dubie and Lou Henry}

Volume 2, Number 1, 2005

URI: https://id.erudit.org/iderudit/1069538ar

DOI: https://doi.org/10.7202/1069538ar

See table of contents

Publisher(s)

First Nations Child and Family Caring Society of Canada

\section{ISSN}

1708-489X (print)

2293-6610 (digital)

Explore this journal

Cite this article

Lafrenière, G., Diallo, P., Dubie, D. \& Henry, L. (2005). Can

University/Community Collaboration Create Spaces for Aboriginal

Reconciliation? Case Study of the Healing of the Seven Generations and Four Directions Community Projects and Wilfrid Laurier University. First Peoples Child \& Family Review, 2(1), 53-66. https://doi.org/10.7202/1069538ar
Article abstract

In this article, the authors attempt to illustrate how two Aboriginal community-based projects were conceptualized and developed through the collaborative efforts of four individuals who believed in the merits of a project aimed at survivors and intergenerational survivors of the residential school system as well as Aboriginal people in trouble with the law. Drawing upon a small body of literature on university/community collaboration, the authors illustrate the importance of meaningful collaboration between universities and communities in order to enhance a mutually beneficial relationship conducive to community-engaged scholarship. Through an examination of the case study of the Healing of The Seven Generations Project and the Four Directions Aboriginal Restorative Justice Project, the authors hope to illustrate to fellow Aboriginal colleagues in Canada the merits, strengths and challenges of university/ community collaboration. Ultimately, what the authors hope to share through this article is an example of how university/community collaboration can create spaces whereby Aboriginal people have become agents of their own healing.
Copyright $\odot$ Ginette Lafrenière, Papa Lamine Diallo, Donna Dubie, Lou Henry, 2005
This document is protected by copyright law. Use of the services of Érudit (including reproduction) is subject to its terms and conditions, which can be viewed online.

https://apropos.erudit.org/en/users/policy-on-use/ 


\title{
Can University/Community Collaboration Create Spaces for Aboriginal Reconciliation?
}

\section{Case Study of the Healing of The Seven Generations and Four Directions Community Projects and Wilfrid Laurier University}

Ginette Lafrenière, Papa Lamine Diallo, Donna Dubie and Lou Henry

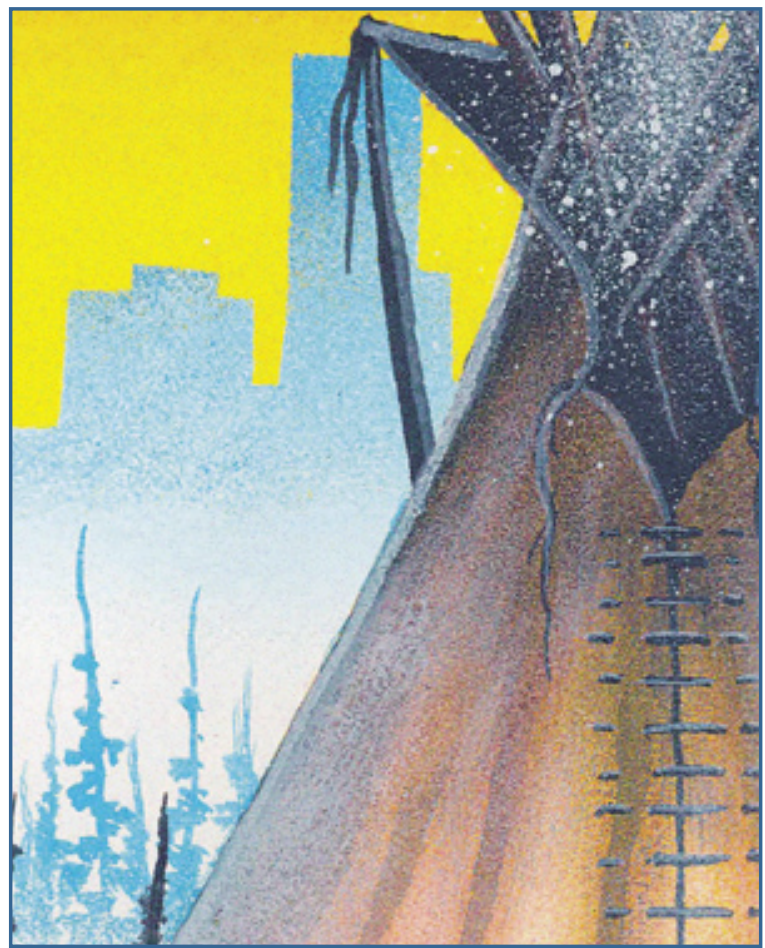

\author{
Abstract \\ In this article, the authors attempt to \\ illustrate how two Aboriginal community- \\ based projects were conceptualized and \\ developed through the collaborative efforts \\ of four individuals who believed in the \\ merits of a project aimed at survivors and \\ intergenerational survivors of the residential \\ school system as well as Aboriginal people \\ in trouble with the law. Drawing upon \\ a small body of literature on university/ \\ community collaboration, the authors \\ illustrate the importance of meaningful \\ collaboration between universities and \\ communities in order to enhance a mutually \\ beneficial relationship conducive to \\ community-engaged scholarship. Through an \\ examination of the case study of the Healing \\ of The Seven Generations Project and the \\ Four Directions Aboriginal Restorative \\ Justice Project, the authors hope to illustrate \\ to fellow Aboriginal colleagues in Canada \\ the merits, strengths and challenges of \\ university/community collaboration. \\ Ultimately, what the authors hope to share \\ through this article is an example of how \\ university/community collaboration can \\ create spaces whereby Aboriginal people \\ have become agents of their own healing.
}




\section{I) Introduction}

Our collaboration within the Healing of The Seven Generations Program and the Four Directions Aboriginal Restorative Justice Project is one that has developed over the past two years. The projects have grown from a desire to "help" to full blown active organizations with too many clients and not enough staff to answer to the overwhelming demand on the services provided by the projects. The demands have surpassed everyone's expectations relative to how badly needed these organizations were to the Kitchener-Waterloo community in Ontario. Organizers are left with little time to reflect on the development and growth of the Healing and Four Directions projects.

On February 23rd, 2005 the Executive Directors of both projects organized a one-day forum whereby all Aboriginal organizations from the Waterloo Region converged to discuss their raison d'être within the community and how alliancebuilding was crucial for both Aboriginal and mainstream organizations in order to best serve Aboriginal clients and community members. Entitled, "Taking Back Our Responsibility", the leadership of the Healing and Four Directions organizations managed to create a safe and nurturing space whereby people could freely talk about the challenges of working with urban Aboriginal peoples. The afternoon was dedicated to highlighting the challenges of working with survivors and intergenerational survivors of the residential schools as well as Aboriginal adults and youth in trouble with the law. Additionally, much time was spent on the merits of collaborating with researchers from Wilfrid Laurier University. Approximately 75 community members, social service workers, students and professors attended the forum. What follows is a brief synopsis of the essence of what was discussed relative to the merits of university/community collaboration.

The article begins by giving some background information on how both projects were conceptualized and informed by the devastating effects of the residential school system. A very brief illustration of the residential school system followed by descriptions of the Healing of The Seven Generations and Four Directions Aboriginal Restorative Justice projects are presented. We then draw upon some of the literature relative to university/community collaboration. We attempt to illustrate the strengths and challenges of our experience of university/ community collaboration. We conclude by illustrating five determining factors, which have informed and continue to inform our alliance building through these projects.

\section{II) Recognizing the need for Innovation and a "Better Practice" when Working with Aboriginal Families}

As employees in an Aboriginal employment service, both Lou Henry and Donna Dubie recognized the challenges of attempting to work with Aboriginal clients who, while seeking employment were often grappling with alcohol or drug addiction issues. As Donna states working in employment with Aboriginal people was not easy:
It's like you're working with $C$ and $D$, but
$A$ and $B$ are missing. I couldn't place any
of my clients because of their issues and I
knew that their issues had to do with the
legacy of the residential school system. To
me, I couldn't place clients in jobs until they
dealt with their personal issues. And when
I would place some of them in jobs, they
would lose them eventually. It was a never-
ending cycle of setting people up for failure.
I was sick.

(Personal communication with

Donna Dubie, August 2004).

Lou also shared Donna's frustration in trying to find employment for unemployable Aboriginal clients. His frustration led him to create, by accident, a restorative justice project. It began after one of his clients in trouble with the law had expressed a desire to be involved in some type of Aboriginal cultural healing project. Commissioned by a local judge who knew something of alternative measures to incarceration, Lou was asked if he could work with this client 
in a restorative justice capacity. Immediately, Lou organized a sentencing circle, an advisory committee and volunteers to work not only with this individual, but others who followed. As Lou shared with researchers at the university in November of 2004, trying to sustain an Aboriginal specific restorative justice project has not been easy:

In addition to doing my regular job, I would do the restorative justice work in the evenings and on the weekends. It was pretty tough, but worth it. Aboriginal people need to know who they are, not be ashamed to be who they are and connect with their culture through Sundance, sweats and healing circles. We provide that to them because all of us who are working with them have been there. We know what it's like. To have an Aboriginal specific restorative justice project is important to this community when you think that we don't even have a Native Friendship Centre in the Waterloo Region. Donna and I definitely fill a gap in Aboriginal service delivery. No doubt about it (Personal communication with Lou Henry, November 2004).

In May of 2003, we (Ginette Lafrenière and Lamine Diallo) met with both Donna and Lou. After colliding socially with Donna, we were approached to assist in the development of an ambitious healing project proposal for survivors and intergenerational survivors of the residential school system. Later, we were introduced to Lou who also wished to transform his volunteer work with Aboriginaloffenders into a full-time program. We agreed to assist, and after many hurdles and revisions to project proposals, both the Healing and Four Directions projects received funding. This enabled Lou and Donna to access a physical location and hire staff.

Before going into more detail relative to the width and breadth of our collaboration, we believe it is important to present a very brief but important illustration of the residential school system given that both Aboriginal projects have emerged as viable organizations in Kitchener-Waterloo. The devastating effects of the residential school system continue to influence and compromise healing processes for many survivors and intergenerational survivors of what we would qualify as Canada's apartheid. The Healing and Four Directions projects are key organizations in the fight to reclaim a sense of justice and healing.

\section{1) Defining the Residential School System}

The residential school system was a politically motivated attempt to systematically assimilate Aboriginal people into the dominant white, European culture of "Canada". Thousands of Aboriginal children across Canada were taken from their homes and institutionalized in residential schools.
The system was officially in effect between 1892 and 1969 through arrangements between the Government of Canada and the Roman Catholic Church, the Anglican Church, the United Church, and the Presbyterian Church. Although the Government of Canada officially withdrew in 1969, some of the schools continued operating throughout the $70 \mathrm{~s}$ and $80 \mathrm{~s}$

(Aboriginal Healing Foundation, 2003, p.54).

In the schools, many children suffered sexual, physical and emotional abuse by the adults who operated them.

Many of these children, in addition to the emotional abuse of being robbed of a family and a culture, were subjected to horrific physical and/or sexual abuse by some of the adults running the schools. Children who tried to escape were beaten, chained, and severely whipped. They were also punished for speaking their language (needles through the tongue was one method used) or for attempting to speak to siblings of the opposite sex (Aboriginal Healing Foundation, 2003, p.57).

According to the Aboriginal Healing Foundation (2003), there were approximately 130 residential schools, which existed in Canada between 1800 and 1990. In fact, the last school to close its doors was Akaitcho Hall in Yellowknife in the 1990's 
(p.2). The residential school system was only an element of a much larger plan to eradicate the "Indian problem" in Canada.

The Indian Act and the Child Welfare, Reservation and Justice systems took over. It is these larger relationships, and the forced assimilationist policy that informs them, which account for much of the varied conditions of Aboriginal life (Aboriginal Healing Foundation, 2003, p.58).

The evidence is overwhelming relative to the disastrous effects of the residential school system in Canada (Chrisjohn, 1992; Milloy, 1999; Native Council of Canada, 1990; Nichol, 2000; Pauktuutit Inuit Women's Association of Canada, 1991; Yellowhorse and Killstraight, 2003). Higher rates of suicide, alcohol and drug addiction, as well as domestic violence are serious challenges, which characterize many urban and non-urban Aboriginal communities across Canada today. The undeniable link between the legacy of the residential school system and social as well as economic inequities amongst Aboriginalpeople needs to be addressed. Even though the cultural apartheid, which characterizes a large piece of Canada's history (something rarely problematized in school curricula), is unmistakably hideous, it is at the same time evidence of the resilience of a people who have resisted complete and total cultural annihilation. Fortunately, there are organizations, community groups and individuals across Canada who, as agents of their own healing, have engaged a process of collective recovery in the hopes of addressing the oppressive legacy of the residential school system. The Healing of The Seven Generations and Four Directions Aboriginal Restorative Justice projects aim to respond to the needs of members of the Aboriginal community in the Waterloo Region (Southwestern Ontario).

\section{2) What does Reconciliation and Healing mean in an Aboriginal Context?}

In order to understand our assertion that university/community collaboration can (c) Lafrenière, Diallo, Dubie and Henry open up spaces for Aboriginal reconciliation, it would seem prudent to take a short look at what the term "reconciliation" means for us as collaborators. There are various definitions available, some which better reflect what we are talking about here. Generally reconciliation can be understood to involve the restoration of relationship. In our case we are concerned with the restoration of relationship that Aboriginal people have with themselves, their families, the Aboriginal community, the wider non-Aboriginal society and the academy. Obviously our collaborative efforts will at times impact possibly one dimension of that restoration but culminate with other efforts at reconciliation that will one day lead to a healthier community for all.

Sutherland (2004) maintains that "the heart of reconciliation is a parallel process of personal and political transformation from systems of domination to relationships of mutuality" (p.1). Our approach to collaboration is one which is etched in a personal understanding by all members of the collaborative, in what it means to experience marginalization and oppression. We also have an understanding of what the personal toll of such experiences can and have been. Throughout the article we refer to the mutuality of our relationship - that ours is a collaboration wherein both the university and the communitybased groups benefit both personally and organizationally from our collective efforts. This takes us away from the traditional view of academe as something that is inaccessible and a place where knowledge is somehow "created" in an academic vacuum far from the community. As a collaborative, we believe that our research is rich and textured, precisely because it is informed by this commitment to mutuality and of wanting to address reconciliation by "bringing together and restoring union". (Lemay and Piotrowski, 2002, p.1).

Sutherland (2004) also delineates a series of shifts that need to take place in order for this reconciliation to take place:

To transform systems of domination into relationships of mutuality, I suggest the following four guiding 
touchstones: drawing on the fundamental worldviews of the parties themselves, transcending the victimoffender cycle, engaging in largescale social change, and assessing appropriate timing and tactics (p.1).

\section{3) Overview of the Healing of The Seven Generations Project}

The Healing of The Seven Generations was conceptualized by Donna Dubie, First Nations intergenerational survivor of the residential school system. The project aims to address the needs of Aboriginal survivors and intergenerational survivors of the residential schools in the Region of Waterloo.

According to the initial proposal submitted to the Aboriginal Healing Foundation, the Healing of The Seven Generations attempts to work with all Aboriginal people and community members that are suffering from the effects of the residential school system. Within the program, Aboriginal people are encouraged to learn about traditional and non-traditional teachings and ways of regaining and maintaining holistic well-being.

\section{Goals of the Project:}

+ To engage Aboriginal people in a safe and nurturing, culture-based group healing process so that they can recognize, address and begin to resolve the healing issues that come from sexual and physical abuse at residential schools and/or the intergenerational impacts of such abuse. These impacts may include family dysfunction, addictive behaviours, violence, abandonment, all types of abuse, low self-esteem, unhealthy relationships, grief and other related problems; + To provide opportunities for learning about Aboriginal traditions, culture and spirituality to Aboriginal people who are survivors of sexual and physical abuse at residential schools or intergenerationally impacted;

- To increase the capacity of service providers to work more effectively with Aboriginal people who are survivors (direct or intergenerational) of residential school abuse;

+ To engage in public education on residential school impacts and abuse recovery;

- To initiate community support systems for individuals impacted by sexual assault and the intergenerational effects of the residential schools;

- To coordinate and ensure active healing partnerships between individuals and other local service providers;

- To employ the services of Elders, to conduct traditional cultural activities, and professional therapists, who are culturally skilled and adept at individual and family counselling; and

- To assist individuals in overcoming trauma in their personal lives so that they are able to stop the cycle of abuse. It is expected that once members of the Aboriginal community are imbued with understanding and knowledge of the past history/legacy of residential schools, Aboriginal people will begin to show signs of reciprocal nurturing and positive connections towards their immediate and extended families as well as towards the community at large (Dubie, 2003).

\section{4) Overview of the Four Directions Aboriginal Restorative Justice Project}

The mandate of this particular initiative is to implement and maintain culturallybased and community driven pre- and postdiversion programs for Aboriginal people. It is committed to providing meaningful alternative measures to the current criminal justice process by implementing healing plans and making referrals, which address the healing and restitution needs of all those involved (complainants, offenders, community, justice system).

The Four Directions Aboriginal Restorative Justice Program works in compliance with section 718.2 (e) of the Criminal Code and with the Youth Criminal Justice Act. It serves Aboriginal people charged with Class 1 and some Class 2, less serious hybrid offences who appear before the courts in Kitchener-Waterloo, 
Cambridge or Guelph. It also serves Aboriginal and non-Aboriginalyouth who have been referred to this program by the police and/or the courts through precharge diversion, as directed by the new Youth Criminal Justice Act of Ontario.

The types of healing (disposition) plans developed vary from client to client. Through sentencing circles, the volunteers who make up the Council learn about the personal issues that the clients have been grappling with and through a series of discussions create a consensus-derived plan which is meant to help guide each client in working on resolving their personal issues. At the same time there is focus on meeting the requirements of the mainstream justice system and making direct or community restitution where possible.

Four Directions plays an instrumental role within the Waterloo Region, as evidenced by the enormous demands placed on the staff and volunteers. Communities outside of the Waterloo Region solicit the services of Four Directions, and as such, the program is expanding throughout Southern Ontario. The executive director of Four Directions works in a variety of capacities including public educator, counsellor, advocate, and consultant to area groups concerned with restorative justice. He is also expanding his services to include fee-for-service arrangements with addiction and recovery organizations (both Aboriginal and non-aboriginal), as well as various detention facilities in Southern Ontario. By connecting Aboriginal people to their roots through circles, sweats, Sundance, and Aboriginal-specific programming, Four Directions Aboriginal

Restorative Justice has enjoyed enormous success. Of the 50 clients who are active within the program, only two known cases of recidivism have occurred.

\section{III) University/Community Collaboration}

The literature is quite clear on how Aboriginal people have suffered and survived the effects of colonization and subsequent (C) Lafrenière, Diallo, Dubie and Henry cultural atrophy through the residential school system (Chrisjohn et al, 1992; Graham, 1997; Grant, 1999; Richardson, G. , Hawks, S. (1995); Royal Commission on Aboriginal Peoples, 1996). Where there are gaps in the literature is in the area of how universities can be viable and equitable partners working with culturally determined groups and how these groups define and demystify the communities in which they operate. The Healing of The Seven Generations and Four Directions Aboriginal Restorative Justice projects are designed to reach out to Aboriginal people in order to address painful issues relative to the effects of the residential school system and the Canadian judicial system.

It appears to us that the nature of these projects is most interesting given that they are operating from a standpoint of "community" where in fact the notion of "community" has long been challenged. For example, what does "community" mean for urban Aboriginals living in KitchenerWaterloo? How can the projects re-create "community" when many of its participants have never experienced the safety and nurturing of a healthy "community"? Is it possible to re-create community and redefine the notion of community for Aboriginal people seeking respite and assistance? And finally, can an academic institution assist in this process of redefinition of community in collaboration with community-based projects? Ultimately, how can university/ community collaboration create spaces for Aboriginal healing and reconciliation when there are no imitable models from which to draw upon? We believe that we have elements of answers with respect to these questions. What appears to be a common denominator within our answers is our belief in the legitimacy of alliance building and our commitment to anti-oppressive work.

In an article on academic/community collaboration, authors Gronski and Pigg (2000) argue that collaboration between universities and community is key to being able to enhance one's capacity to serve marginalized members of society. Quoting Walsh (1997), the authors describe the 
need for renewed collaboration between various stakeholders in the community:

The multiple and often messy needs of families and communities require a renewed collaboration among business, government, non-profit services and local groups (p.3).

Unfortunately, not everyone shares our enthusiasm for university/community collaboration given that it is still somewhat misunderstood in traditional academic settings. We believe that this climate is slowly changing as evidenced by various funders in Canada who have understood the connection between scholarship and community research. In a recent report on communitybased work, the authors discuss certain challenges to what they term as "communityengaged" work, but what we would qualify as university/community collaboration:

The report examines a number of critical challenges that communityengaged scholarship poses to the predominant paradigm of faculty incentives in health professional schools. These include the tendency of faculty peers to classify communityengaged work as service rather than to consider the factors that might qualify the work as genuine scholarship, the under valuing of the role of products of scholarship that are not in the form of peer-reviewed journal articles, and the limited role of community partners in faculty review, promotion and tenure processes (Commission on Community-Engaged Scholarship in the Health Professions, 2005).

As collaborators within the Healing of The Seven Generations and Four Directions projects, we believe that, despite certain challenges, the symbiotic relationship, which has emerged between the projects and Wilfrid Laurier University, has served to create an energy which has been mutually satisfying both from an intellectual and practical standpoint. It has not been without its difficulties given the fact that working for a year on the development and implementation of such projects has invited queries from our colleagues in terms of the legitimacy of engaging in such a labour intensive endeavour for very little money. According to Marullo and Edwards (2000), "the academic reward system... values most highly the science of discovery and offers fewer incentives for faculty to engage in the scholarships of application, integration and pedagogy". As newcomers to Laurier, we are often gently and, at times, not so gently reminded that we are to publish and engage in intellectual work, which is meaningful and important. We would argue that this is precisely what we have done by working with these projects and documenting for over a year the trials and tribulations of getting such projects off the ground. We have also examined the role that we have played as academics in terms of facilitating this process. Boyer (1999) speaks to this notion of what we would qualify as "academic repositioning", but what he qualifies as "scholarship of engagement", whereby universities are inevitably reshaped as they enter into partnerships with various actors within the community.

Marullo and Edwards (2000) support this idea as evidenced by the following quote: ... the engaged scholar weaves together local or regional constituencies... they must also play the role of organizer among their university colleagues so that networks of interested faculty, administrators, and staff can collaborate with enduring communitybased constituencies and develop innovative "win-win" projects for all parties.

Author Barri Tinkler (2004) states, "Community-based research (CBR) is a new movement in higher education that combines practices from other participatory research models as well as service-learning. CBR requires researchers to work closely with the community" (p.22). Refraining from comment on the notion that communitybased research is such a "new" movement, we would however submit that much of the labour intensive work in which we've engaged with one another as collaborators has been more about process than it has been about a quantifiable outcome. This fact alone has raised a few eyebrows in our academic spaces. What we attempt to explain to anyone who 
wishes to understand the nature of our work is that we continue to work together because we enjoy doing so. Not a week goes by where there isn't a new opportunity to design a creative workshop, or submit a paper to a conference or access funding for an innovative project related to the work of both the Healing and Four Directions programs. We do this work because it sustains us, nurtures us and fuels our belief that what we are doing collectively is important work.

Part of what makes our collaboration with the Healing of The Seven Generations and Four Directions a win-win situation is the free flow of information, expertise and learning that has occurred in the past year. Certainly our students have benefited from Donna and Lou's presence within the university. We anticipate that in the future their programs may well benefit from the presence of progressive and dynamic Aboriginal Master of Social Work placement students within their programs. As academics, we have certainly learned a great deal with respect to challenging the most basic assumptions of community organizing that we have held for a long time. For example, the issue of intercommunity violence and notions of trust are prevalent themes, which we have discussed at great length with members of the Healing and Four Directions projects.

As academics we are forced to consider the enormous complexities of community organizing and development within a community, which does not have a strong base of trust or collaboration. This makes for difficult outreach when attempting to initiate new and innovative community-based projects. Since the forum in February 2005, we have witnessed positive movement in this direction, given the leadership of both Donna and Lou who managed to organize all Aboriginal organizations in the Waterloo Region to converge upon a one-day forum on Aboriginal issues and service provision. This, apparently, is a notable endeavour within the Aboriginal community, which does not have a long tradition of inter-agency collaboration.

Our journey with both projects enables us to draw comparisons and chart the (c) Lafrenière, Diallo, Dubie and Henry progression of the evolutionary nature of the projects. As such, there is certainly much room for reflection and research in terms of how to address and redress the conceptualization and delivery of community projects, which are mutually nurturing and supportive within Aboriginal spheres. While much has been written on the issue of modern anthropology theoretically shaped by colonial conquest and imperialism, we would highlight the writings of Celia HaigBrown (2001) who states the following:

$$
\begin{aligned}
& \text { Perhaps it is my white skin privilege } \\
& \text { which leads me in the final analysis to } \\
& \text { an incessant desire to contribute to a } \\
& \text { project of (re) building the university } \\
& \text { in a way which acknowledges its } \\
& \text { strengths, recognizes its historic } \\
& \text { shortcomings, and feels a need } \\
& \text { to shift priorities and redefine its } \\
& \text { "business" in an effort to address } \\
& \text { some conception of social justice. }
\end{aligned}
$$

We contend that our collaboration utilizes its various strengths as feminist and minoritized researchers within academe to create spaces for community projects like the Healing of The Seven Generations and Four Directions Aboriginal Restorative Justice. This has been undertaken in order to enhance the Aboriginal community's capacity to design their own healing and empowerment. Inversely, the creation of such space also means that, through various educational forays, our students and colleagues are sensitized to the needs of Aboriginal people as articulated by Aboriginal people themselves.

This brings us to what motivates us to engage in such a process in the first place. As social justice advocates who are coming from social locations which are quite different (African, Franco-Ontarian and First Nations) we come from spaces which not only understand the notion of oppression and marginalization, but through our research and our work in the community, wish to encourage marginalized communities to feel secure in their attempts to be agents of their own transformative community work. We assert that being able to engage in community-based research and 
meaningful collaboration can invariably create spaces for healing and therefore reconciliation within Aboriginal spheres.

As we have attempted to discuss in the past, and continue to reflect upon today, non-Aboriginalresearchers can play a role as "allies" as long as we know where to draw healthy boundaries with the communities in which we operate. What has been and remains helpful in our work with the Healing and Four Directions projects is that we are not well versed in issues relative to the effects of the residential school system. We had not even heard of restorative justice until meeting Lou Henry. Inversely, neither Donna nor Lou had any contacts with the university prior to meeting the researchers and had not thought about valuing research as an integral part of their projects.

Over the course of the past two years, all four collaborators have experienced the benefits of working collectively. What the university collaborators bring to the table is: an interest in research; expertise in demystifying funding applications; access to resources at the university; networks of researchers who can assist with certain elements of, for example, program development; and, a host of other tools which may have little to do with Aboriginal healing, but overall can benefit the work in which both Lou and Donna are involved. This, to us, is precisely what makes our collaboration equitable. We are a collective of people bringing various strengths to the table. What follows is a table of concrete examples illustrating how we mutually benefit by working together (See Table 1). We conclude with a series of determining factors, which have enhanced our collaboration thus far.

\section{IV) Determining Factors which have Enhanced our Collaboration}

Given our commitment to our collaborative work, we would qualify that our partnership can be etched within an "alliance-building" framework. What this means concretely is that not only have we forged connections amongst ourselves, but we utilize these connections to build bridges with other partners and allies in order to continue making inroads within Aboriginal and non-Aboriginal spheres. While the nature and depth of both the Healing and Four Directions projects must at all times be Aboriginal-specific, it is also flexible enough to embrace, on their terms, outreach to non-Aboriginalclients requesting assistance. For example, at the present moment, both projects have received referrals from the Waterloo Regional Police. On occasion, non-Aboriginalclients benefit from the teachings of Aboriginal people. As one program coordinator commented to us during the Aboriginal Forum held in February 2005, it would appear that it is sometimes beneficial for Aboriginal people to see that non-aboriginals also grapple with, for example, addictions and domestic violence. Admittedly, there are, at times, very animated discussions on the merits of having heterogeneous circles with both Aboriginal and non-Aboriginalclients. What is curious in this debate is the fact that it is the non-Aboriginalpartners who question the logic of such generosity.

As mentioned earlier, despite the challenges, we would assert that there are determining factors, which have positively and continue to enhance our collaboration. They are as follows:

\section{Our initial collaboration grew out of a shared commitment to social justice and, as such, a resulting friendship emerged.}

As individuals we have a long history of working in spheres of social change and social action, so the "buy-in" to work collectively was easy. With respect to the notion of "alliance-building", it has been our experience that taking the time to get to know one another was important for our relationship. According to authors Thompson, Story, and Butler (2002), collaborative relationships take time, and persistence signals sincere and serious intention.

Our working relationship was forged over a long period of time, which permitted us to get to know one another 


\section{Table 1: Symbiotic Factors Contributing to Mutual Satisfaction and Challenges of Collaborative Work Between the Healing of The Seven Generations, Four Directions Aboriginal Restorative Justice and Researchers at Wilfrid Laurier University.}

\section{Wilfrid Laurier University}

Healing of the Seven Generations \& Four Directions Aboriginal Restorative Justice

\begin{tabular}{|c|c|}
\hline BENEFITS & BENEFITS \\
\hline $\begin{array}{l}\text { ability for researchers and students to be } \\
\text { in touch with issues in the community in a } \\
\text { meaningful way given the presence of both } \\
\text { Executive Directors in class and extra-curricular } \\
\text { contexts } \\
\text { ability to share valuable and impactful teachings } \\
\text { relative to enhancing social work practice with } \\
\text { Aboriginal populations } \\
\text { healthy challenges relative to social work } \\
\text { practices which can only occur by having people } \\
\text { in the academic sphere who feel safe enough to } \\
\text { critique and share personal stories of tragedy } \\
\text { and triumph relative to healing } \\
\text { students, faculty and staff are able to demystify } \\
\text { Native people and culture and ask questions } \\
\text { without fear of ridicule } \\
\text { student and faculty are able to access } \\
\text { Aboriginal projects for research, learning, and } \\
\text { volunteerism } \\
\text { researchers are privy to dynamics of the work in } \\
\text { which both Executive Directors are involved } \\
\text { researchers get to know clients on a social level } \\
\text { researchers can get an in-depth view of the } \\
\text { challenges of healing work }\end{array}$ & $\begin{array}{l}\text { assistance in navigating various } \\
\text { bureaucracies in town } \\
\text { university is a credible partner for some } \\
\text { funders as evaluation is at times an } \\
\text { important component within the context } \\
\text { of a project proposal } \\
\text { researchers are able to demystify the } \\
\text { process of applying for funding } \\
\text { learning about research is enjoyable and } \\
\text { empowering as the creation of a research } \\
\text { caucus for both projects has been } \\
\text { initiated } \\
\text { researchers are strong advocates for both } \\
\text { projects within the community } \\
\text { both projects get to promote their } \\
\text { programs within the university through } \\
\text { conferences, class presentations, etc... } \\
\text { and also influence and sensitize future } \\
\text { social workers at the Faculty of Social } \\
\text { Work } \\
\text { both Executive Directors of the projects } \\
\text { have the opportunity to inform and } \\
\text { shape course content of several courses at } \\
\text { the Faculty of Social Work }\end{array}$ \\
\hline CHALLENGES & CHALLENGES \\
\hline $\begin{array}{l}\text { demands on time which can be very consuming } \\
\text { and compromise other priorities relative to } \\
\text { work/research/life balances } \\
\text { at times, seeming incompatibilities relative to } \\
\text { time and organizational issues (for example, } \\
\text { a bureaucratic dance is always engaged when } \\
\text { smudging is to take place in a public forum at } \\
\text { the university given issues relative to university } \\
\text { smoking policy); } \\
\text { some university colleagues may question the } \\
\text { intimate proximity which is enjoyed with } \\
\text { community collaborators }\end{array}$ & $\begin{array}{l}\text { university bureaucracy is most } \\
\text { frustrating (for example, to be issued a } \\
\text { reimbursement cheque for community } \\
\text { collaborators is a long process; } \\
\text { innumerable parking tickets are acquired } \\
\text { when meetings take place on campus as } \\
\text { well as very strict rules around smoking } \\
\text { both within and outside the university } \\
\text { campus buildings) } \\
\text { at times, both Executive Directors } \\
\text { may feel that their message may not } \\
\text { be understood by the majority of } \\
\text { non-Aboriginal students and Faculty } \\
\text { members } \\
\text { the university setting is not always a } \\
\text { welcoming or safe environment to share } \\
\text { aspects of one's life or culture }\end{array}$ \\
\hline
\end{tabular}


and as a result an emerging friendship ensued. While some may think that merging friendship and collaboration is inadvisable, we would respectfully join Shragge (2003) in submitting that the basis of many social action or social change collaborations is etched first and foremost in personal relationships.

2. What brought us together were individuals not institutions.

It is important for us to highlight that while we are connected to academic and community institutions, we are quite clear on the concept that the chemistry, which we have as individuals was what brought us together initially, and what sustains our mutual enthusiasm to keep working in a collaborative fashion. Alliance building for us is not so much about dealing with the "other" in an "institution" but with individuals with whom we believe we can get along. While this may sound simplistic (and we recognize that it is) we also recognize that after 17 years of community organizing, both in Canada and abroad, we have learned that the notion of an "ally", on the purest and simplest level, has to do with the individual and not the institution which s/he represents.

\section{There was a strong common denominator of oppression and marginalization as experienced by someone who is African and individuals who are Aboriginal.}

Not to negate Ginette's experience of oppression and marginalization (or her contribution to the collaboration), it is most legitimate to state that given our respective experiences with the devastating effects of colonization both in Africa and here in Canada, there is a silent and recognizable mutuality of experience relative to the experience of colonization. There is very little research which points to alliance building between African and Aboriginal people in Canada, but we would submit that we are "natural" allies even though the present-day effects of colonization in our respective geographic spheres may be quite different. As such, our collaboration with the Healing of The Seven Generations is a way to manifest solidarity for Indigenous people everywhere who continue to suffer and, more importantly, resist the colonizer's design of cultural and economic suffocation.

4. There was strong leadership on the part of the initiators of the projects and as such partners were very clear about mutual expectations.

Without a doubt, Donna Dubie's vision and strong leadership has brought the Healing of The Seven Generations to a space of respect and much solicitation. At the beginning of our alliance, Donna was very clear as to what her expectations were: she required some assistance with the mechanics of submitting a proposal and needed a sponsor until she was incorporated as a non-profit. Upon reflection, the key determining factor, which influenced the initial journey was the fact that Donna was able to take a risk and ask for help. She also knew instinctively that there was perhaps some merit in developing an alliance with an academic institution.

As for Lou's project, his is one that is more labour-intensive at the moment given that he has not received as much funding as the Healing Project. His project however, has enormous potential to thrive given the overwhelming community response, which he has received during the past year. Research actually plays a much more prominent role in his project than Donna's at the moment, given the nature of the funding which he has received.

Another key determining factor, which has permitted us to sustain our alliance, is that we, as academics, have been very clear with both Lou and Donna with respect to what we can or cannot contribute to the project. At the beginning of our working relationship, we articulated that we had no experience whatsoever working on any aspect of residential school system redress nor did we know anything about restorative justice issues. We are not clinicians and as such could not and cannot offer anything in terms of how to deal with the effects of sexual abuse, for example. What we did articulate is that we are interested in university/community collaboration and we would be most interested in documenting 
the relationship between the projects and the university. We would also assist in accessing funding to help sustain the projects and help create spaces whereby we could mentor members of the Healing of The Seven Generations and Four Directions projects in matters of research and data collection. We also offered our documentarymaking services to shoot a video on each project in order to facilitate dissemination of information relative to the projects. As a result of our alliance, we identified people who worked as videographers, as well as individuals who are involved in arts-based social development work. As a result two documentary videos have been created and an Aboriginal theatre group has emerged through this collaborative. Inversely, our university has benefited much in terms of having members of the project and the larger Aboriginal community help our students and colleagues understand the devastating effects of the residential school system on Aboriginal people in Canada. For us as academics, we certainly have been challenged and encouraged to reflect upon Eurocentric ways of writing and engaging in meaningful community-based research.

\section{Academic partners had for the most part very supportive academic work environments, which encouraged such community-based work.}

We believe that if allies, working in academic institutions, wish to collaborate with Aboriginal communities in any manner, they need to have nurturing and supportive work environments. It is very important that academic workplaces show great flexibility in order to accommodate community partners. A simple task such as accessing parking passes for community collaborators can be most helpful in creating accessibility for our partners. Larger issues, such as valuing community-based research, are also essential in sustaining the enthusiasm for one's commitment to this type of research.

\section{V) Conclusion}

Since the beginning of this journey, our alliance has been both intellectually and (C) Lafrenière, Diallo, Dubie and Henry personally satisfying. Given that our collaboration is still in its infancy stage, there is much room for future research on how our work has evolved and been shaped by our mutual collaboration. We believe strongly that our alliance works because of the determining factors described above. These are influences, which are specific to this particular alliance, and should be viewed and appreciated as such.

We have, however, taken the time to share our experiences because even though these determining factors are specific to both the Healing and Four Directions projects, we believe that they may be useful in inspiring others in academic institutions and communities engaged in similar types of partnerships. Of particular importance is the attention, which we, as a collective, have purposefully attributed to our own social locations and how our experiences with marginalization have informed the way we are committed to this project. Of note is the fact that we believe that the personal friendship, which we've developed not only with Lou and Donna but other members of the project, is fundamental in making this alliance an honest success.

Future research on the impact of the project on consumers of the programs as well as the evolving relationship between Wilfrid Laurier University and the Healing and Four Directions projects will inevitably mean opening up our alliance to fellow collaborators. It is hoped that in the future we will also have a clearer, more well defined illustration of the dynamics of each and every one of the determining factors, which have shaped our collaboration thus far. What is important to us as allies is to continue in our commitment to creating spaces whereby academia and community can work together in order to enhance the lives of members within various Aboriginal communities living in the Region of Waterloo.

Can university/community collaboration create spaces for Aboriginal reconciliation? We believe that our collaboration illustrates certain examples, which would lead us to answer "yes". Evidently we have much work ahead of us to truly show the evidence of the 
work that we do and the claim that we make that university/community collaboration can be empowering to Aboriginal spheres and thus Aboriginal reconciliation. We are most painfully cognizant of the fact that historically, Aboriginal people have not been the benefactors of research executed in Aboriginal milieus. What we hope our collaboration does, is help to turn the table on years of academic exploitation in favour of a model, which may be viewed as imitable.

\section{Authors' Note:}

Certain segments of information contained herein have been illustrated in other academic forums particularly around the information sharing on the Healing and Four Directions projects as well as pieces of the literature review. The result of this particular article is more of a reflective presentation on the strengths and challenges of our collaboration and the meanings, which we attribute to our partnership and how it relates to the broader work of Aboriginal reconciliation between two Aboriginal projects in Kitchener-Waterloo. There are several more articles that can and will be teased out and expanded upon in the coming years regarding this collaboration. Here we try to give the reader an introduction to the first stage of our work together. We are grateful to our colleagues in Winnipeg and the two reviewers for the opportunity to illustrate our partnership through this medium.

\section{Ginette Lafreniere}

Ginette is an assistant professor at the Faculty of Social Work at Wilfrid Laurier University. She teaches in the area of diversity, oppression and marginalisation, community interventions and research. She is the Director of the Social Innovation Research Group which values universitycommunity collaboration. She is currently engaged in research relative to community interventions with survivors of the residential school system and best practices for social service providers working with survivors of war, torture and organized violence in Africa.

\section{Papa Lamine Diallo}

Lamine is an assistant professor at Wilfrid Laurier University (Brantford Campus) in Organizational Leadership Studies. Lamine has worked for many years within various ethnocultural spheres, primarily working on issues relative to social inclusion of African communities. He is the President of the African Association of the Region of Waterloo as well as the current Chairperson of the Healing of the Seven Generations. $\mathrm{He}$ is involved in several projects aimed at enhancing capacity building for African and Aborignal people in the Waterloo Region. His research interests include non-profit management and collaboration, decentralized cooperation and international development as well as race relations amongst francophone Africans in Ontario and Quebec.

\section{Lou Henry}

Lou Henry is the founding Executive Director of the Four Directions Aboriginal Restorative Justice Project in Kitchener, Waterloo. He works with adults and youth offenders through sentencing circles and aboriginal-specific healing plans in order to restore personal and spiritual balance in the lives of Aboriginalpeople. He has recently produced a video on his project which is gaining enormous popularity in the province of Ontario due to the low rates of recidivism of the Four Directions project.

\section{Donna Dubie}

Donna Dubie is the founding Executive Director of the Healing of the Seven Generations Project (H7G) which is a community-based initiative aimed at redressing the traumas endured by the survivors and intergenerational survivors of the residential school system. Donna enjoys enormous success within the community as evidenced by the overwhelming amount of people utilizing and benefiting from the services which $\mathrm{H} 7 \mathrm{G}$ provides. She too, has recently produced a video on the merits of university-community collaboration and the work which she does with the Aboriginalcommunity in the Region of Waterloo. 


\section{References}

Aboriginal Healing Foundation. (2003). Where are the children? Ottawa: Legacy of Hope Foundation.

Battiste, Marie. (1986). Micmac literacy and cognitive assimilation. In J. Barman, Y. Hebert, $\& \mathrm{D} . \mathrm{McC}$ askill (Eds.), Indian education in Canada, Volume 1: The legacy. Vancouver: University of British Columbia Press.

Battiste, M., \& Henderson Youngblood, J. (2000). Indigenous knowledge and heritage: A global challenge. Toronto: University of Toronto Press.

Behar, R. (1996). The vulnerable observer. Boston: Beacon Press.

Boyer, E.L. (1990). Scholarship reconsidered: Priorities of the professorate.

Princeton, NJ: Carnegie Foundation for the Advancement of Teaching.

Commission on Community-Engaged Scholarship in the Health Professions. (2005).

Report of the National Commission. Kellogg Foundation. Retrieved February 2, 2005 from http://depts.washington.edu/ccph/kellogg3.html

Chrisjohn, R. et al. (1992). Faith Misplaced: Lasting effects of abuse in a First Nations Community. Canadian Journal of Native Education. Vol. 18, No.2.

Dubie, D. (2003). Proposal for the Healing of The Seven Generations Project, submitted to the Aboriginal Healing Foundation.

Graham, E. (1997). The Mush Hole. Waterloo: Heffle Publishing.

Gronski, R. and Pigg, K. (2000) University and Community Collaboration: Experiential Learning in Human Services, American Behavioral Scientist. Vol. 43, No. 5, February.

Haig-Brown, C. (2001). Continuing collaborative knowledge production: Knowing when, where, how and why. Journal of Intercultural Studies, 22(1).

Lemay, A. \& Piotrowski, L. (2002). The reconciliation model: A conceptual framework.

Retrieved on June 24, 2005 from http://www.rgco. org/articles/lisa_piotrowski_Discovery_2003.pdf

Marullo, S., \& Edwards, B. (2000). From charity to justice: The potential of universitycommunity collaboration for social change. American Behavioral Scientist, 43(5).

Milloy, J. (1999). A National Crime: The Canadian government and the residential School system, 1879 to 1986 . University of Manitoba Press.
Family: Traditions and Adaptations in Proceedings of the 1983 meeting of the Canadian Psychiatric Association Section on Native Mental Health. Ottawa: Canadian Psychiatric Association.

Nichol, R. (2000). Factors contributing to resilience in Aboriginal persons who attended residential schools. Winnipeg: Master's Thesis: Dept. of Social Work, University of Manitoba.

Pauktuutit Inuit Women's Association of Canada. (1991). Arnait: The Views of Inuit Women on Contemporary Issues. Ottawa. The Association.

Richardson, G. and Hawks, S. (1995). A practical approach for enhancing resiliency within families. Family Perspective. 29(3).

Royal Commission on Aboriginal Peoples. (1996). Report of the Royal Commission. Ottawa: Government of Canada.

Shragge, E.(2003). Activism and social change: Lessons for community and local Organizing. Peterborough, Ontario. Broadview Press.

Sutherland, J. (2004). Reconciliation From The Inside Out: Worldviewing Skills for Everyone. Retrieved on June 24, 2005 from http://www.worldviewstrategies. com/e-newsletter/november.html

Thompson, L., Story, M., \& Butler, G. (2002). A collaboration model for enhanced community participation. Policy, Politics and Nursing Practice, 3(3).

Tinkler, B. (2004). Establishing a conceptual model of community-based research through contrasting case studies. Retrieved on February 2, 2005 from httpp://comm.-org.utoledo.edu/papers

Yellowhorse, M. \& Killstraight, B. (2003). Historical trauma, Indigenous knowledge and healing. Ottawa: National Aboriginal Health Organization Conference. 